\title{
Accumulation and apparent oxidation of cis,trans-18: 2 isomers relative to linoleic acid in rats
}

\author{
Zhen-Yu Chen ${ }^{1}$, Kwok Yiu Kwan ${ }^{1}$ and Yu Huang ${ }^{2}$ \\ Departments of ${ }^{1}$ Biochemistry and ${ }^{2}$ Physiology, The Chinese University of Hong Kong, Shatin, NT, Hong Kong, China
}

(Received 13 July 2000 - Revised 11 December 2000 - Accepted 7 February 2001)

\begin{abstract}
Dietary cis,trans-18:2 isomers impair desaturation and elongation of linoleic acid $(\Delta 9$ cis,12cis-18:2), but little is known of their proportional partitioning between accumulation and oxidation. The present study was therefore designed to assess the accumulation and apparent oxidation of cis,trans-18:2 isomers compared with that of trans-18:1 isomers and $\Delta 9$ cis, 12 cis-18:2 in rats. Accumulation is defined as whole-body increase in a fatty acid during a given period (i.e. final body content-initial body content). The apparent oxidation (disappearance) is defined as whole-body utilization of a fatty acid relative to its intake for a given period (intake-excretion-accumulation-longer-chain products)/intake $\times 100$ ). The animals were fed on a diet containing $15 \%(\mathrm{w} / \mathrm{w})$ partially hydrogenated rapeseed oil with $1.72 \%$ energy as cis,trans $-18: 2$ isomers and varying amounts of $\Delta 9$ cis, 12 cis $-18: 2$. The apparent oxidation of total cis,trans-18:2 isomers (72-76\% dietary intake) was greater than that of $\Delta 9$ cis, 12 cis-18:2 (38-51\% dietary intake) but it was similar to that of total trans-18: 1 isomers (78-82\% dietary intake). Among the four isomers, the apparent oxidation of $\Delta 9$ trans,12trans-18:2 was greater than that of the other isomers including $\Delta 9$ trans,12cis-18:2, $\Delta 9$ cis, 12 trans-18:2 and $\Delta 9$ cis, 13 trans-18:2. Accumulation of $\Delta 5$ cis, 8 cis, 11 cis, 15 trans $-20: 4$ and $\Delta 5$ cis,8cis,11cis,14trans-20:4 derived from chain-elongation and desaturation of $\Delta 9$ cis, 13 trans-18:2 and $\Delta 9$ cis,12trans-18:2 was decreased when the dietary $\Delta 9$ cis, 12 cis- $18: 2$ supply was increased.
\end{abstract}

Linoleic acid: Oxidation: cis,trans-18 : 2 isomers: Partially hydrogenated rapeseed oil: trans-Fatty acids: trans-Linoleic acids

Several cis,trans-isomers of linoleic acid $(\Delta 9$ cis, $12-$ cis-18:2) present in the Western diet are formed during refining or partial hydrogenation of vegetable oils. These isomers include mainly $\Delta 9$ cis,13trans-18:2, $\Delta 9$ cis, $12-$ trans-18:2, and $\Delta 9$ trans, 12 cis-18:2 (Ratnayake \& Pelletier, 1992; Ratnayake et al. 1993). Previous investigations have found that human adipose tissue and breast milk contain these cis,trans-18:2 isomers and have a similar isomeric distribution to that in partially hydrogenated vegetable oils (Chen et al. 1995a,b). This finding suggests that these isomers can accumulate in the body and transfer from the maternal diet to the breast milk.

cis,trans-18:2 isomers may interfere with the metabolism of essential fatty acids (Holman et al. 1991). First, they impair elongation and desaturation of $\Delta 9$ cis, 12 cis-18:2, thus reducing the formation of arachidonic acid $(\Delta 5 \mathrm{cis}$, 8 cis,11cis,14cis-20:4). Second, some of these dietary cis,trans-18:2 isomers can be desaturated and chainelongated to form unusual cis,trans-20:4 isomers
(Ratnayake et al. 1994). In fact, $\Delta 9$ cis,12trans-18:2 and $\Delta 9$ cis,13trans-18:2 have been shown to be desaturated and elongated to form two unusual 20:4 isomers, i.e. $\Delta 5 \mathrm{cis}, 8 \mathrm{cis}, 11 \mathrm{cis}, 14 \mathrm{trans}-20: 4$ and $\Delta 5 \mathrm{cis}, 8 \mathrm{cis}, 11 \mathrm{cis}$, 15trans-20:4 in the rat liver (Hill et al. 1990; Koletzko, 1992; Ratnayake et al. 1994). Subsequently, these cis,trans-20:4 isomers may, via lipoxygenase and cyclooxygenase pathways, serve as precursors of unusual eicosanoids with unknown structure and functions (Berdeaux et al. 1996). Thus, it is important to understand the metabolic fate and tissue deposition of these cis,trans-18: 1 isomers.

Despite several decades of research on the metabolism of trans-fatty acids and their possible influence on the metabolism of essential fatty acids, little is known about their partitioning between accumulation and oxidation in whole animals. Studies in rat heart homogenates and liver mitochondria showed that trans-18:1 isomers were oxidized more slowly than their cis-counterparts (Lawson

Abbreviations: FAME, fatty acid methyl esters; LCP, longer-chain products; PHRO, partially hydrogenated rapeseed oil.

* Corresponding author: Dr Zhen-Yu Chen, fax +852 2603 5123, email zhenyuchen@cuhk.edu.hk 
\& Holman, 1981; Lanser et al. 1986). In contrast, human heart homogenates were found to oxidize trans-18:1 and oleic acid ( $\Delta 9$ cis-18:1) at a similar rate (Lanser et al. 1986), which is in agreement with the results of another study in human subjects fed ${ }^{13} \mathrm{C}$-labelled fatty acids, that showed no difference in the oxidation rate of trans-18:1 and cis-18:1 (Delany \& Bray, 1993). However, limited data are available regarding the oxidation rate of cis,trans-18:2 isomers relative to $18: 2 n-6$ except one study that demonstrated that the former were oxidized more readily in isolated rat liver (Ide \& Sugano, 1984).

The results of in vivo oxidation of trans- fatty acids using radioisotopic methods reflect their utilization in intact organisms during the time after administration of the isotopically labelled trans-fatty acids. In contrast, the balance method measures the long-term utilization of a trans-fatty acid. The method of whole-body fatty acid balance was used previously to assess the partitioning between oxidation and accumulation of $\Delta 9 \mathrm{cis}, 12 \mathrm{cis}-18: 2$ and linolenic acid ( $\Delta 9$ cis, 12 cis, 15 cis-18:3) under various conditions (Ide \& Sugano, 1984; Yang et al. 1994; Chen et al. 1996). To our knowledge, data on whole-body retention and oxidation of cis,trans-18:2 isomers relative to their intake are not currently available. Thus, the present study used the balance method to determine oxidation, retention, elongation and desaturation of cis,trans-18:2 isomers in whole animals.

\section{Materials and methods}

\section{Diet}

Rats were fed one of five diets containing $15 \%$ (w/w) rapeseed oil (diet A) or partially hydrogenated rapeseed oil (PHRO; diet B) supplemented with free $\Delta 9 \mathrm{cis}, 12 \mathrm{cis}-18: 2$ at 0.25 (diet C), 0.50 (diet D) and $1.25 \%$ energy (diet E). Other components of the diets are shown in Table 1 . The diets were prepared every 2 weeks and stored at $-4^{\circ} \mathrm{C}$. The PHRO was supplied by Canamera Food (Toronto, Ont., Canada) and the trans-fatty acid content was $27 \cdot 8 \%$ total fatty acids. Non-hydrogenated rapeseed oil was purchased locally in Hong Kong (Lam Soon Oils \& Fats Co., Hong Kong, China). The trans-isomer content of non-hydrogenated rapeseed oil was found to be $0.59 \%$ total fatty acids (reference diet A), as they can be generated during the refining process. Other ingredients were purchased from Harlan Teklad (Madison, WI, USA) except for choline bitartrate and DL-methionine which were obtained from Sigma (St Louis, MO, USA). The fatty acid contents of the diets $(\mathrm{g} / \mathrm{kg})$, as determined by, are GLC, are given in Table 1.

\section{Animals}

Male Sprague-Dawley rats (2 months old, weight $67 \pm 6 \mathrm{~g}$, Laboratory Animal Service Centre, The Chinese University of Hong Kong) were divided randomly into five groups (ten rats per group) and housed in stainless-steel wire-bottomed cages in an animal room maintained at $25^{\circ} \mathrm{C}$ with $12 \mathrm{~h}$ lightdark cycles and $50 \%$ humidity. Food intake was measured daily and body weight was recorded every second day. Animals had free access to food for 3 weeks. Six animals
Table 1. Composition of experimental diets ( $\mathrm{g} / \mathrm{kg}$ diet)

\begin{tabular}{|c|c|c|c|c|c|}
\hline Diets... & $A$ & B & $\mathrm{C}$ & $\mathrm{D}$ & $E$ \\
\hline Casein & $235 \cdot 0$ & $235 \cdot 0$ & $234 \cdot 6$ & $234 \cdot 3$ & 233.4 \\
\hline Maize starch & $288 \cdot 0$ & $288 \cdot 0$ & 287.5 & $287 \cdot 1$ & $286 \cdot 1$ \\
\hline Sucrose & $243 \cdot 0$ & $243 \cdot 0$ & $242 \cdot 6$ & $242 \cdot 3$ & $241 \cdot 4$ \\
\hline Cellulose & $32 \cdot 0$ & $32 \cdot 0$ & $31 \cdot 9$ & 31.9 & $31 \cdot 8$ \\
\hline Mineral mix (AIN-76) & $35 \cdot 0$ & $35 \cdot 0$ & $34 \cdot 9$ & 34.9 & $34 \cdot 8$ \\
\hline Vitamin mix (AIN-76A) & $10 \cdot 0$ & $10 \cdot 0$ & $10 \cdot 0$ & $10 \cdot 0$ & 9.9 \\
\hline Choline bitartrate & $4 \cdot 0$ & $4 \cdot 0$ & $4 \cdot 0$ & $4 \cdot 0$ & $4 \cdot 0$ \\
\hline DL-Methionine & $3 \cdot 0$ & $3 \cdot 0$ & $3 \cdot 0$ & $3 \cdot 0$ & $3 \cdot 0$ \\
\hline Fat $^{\star}$ & $150 \cdot 0$ & $150 \cdot 0$ & $151 \cdot 5$ & $152 \cdot 5$ & $155 \cdot 6$ \\
\hline $16: 0$ & $8 \cdot 6$ & 8.4 & $8 \cdot 4$ & 8.4 & $8 \cdot 4$ \\
\hline $18: 0$ & $3 \cdot 8$ & $10 \cdot 1$ & $10 \cdot 1$ & $10 \cdot 1$ & $10 \cdot 1$ \\
\hline $20: 0$ & $1 \cdot 1$ & 0.4 & 0.4 & 0.4 & $0 \cdot 4$ \\
\hline $22: 0$ & $<0.1$ & 0.4 & 0.4 & 0.4 & 0.4 \\
\hline Total saturates & 13.5 & $19 \cdot 2$ & $19 \cdot 2$ & $19 \cdot 2$ & $19 \cdot 2$ \\
\hline $16: 1 n-7$ & 0.4 & 0.3 & 0.3 & 0.3 & 0.3 \\
\hline $18: 1 n-9$ & 83.5 & $73 \cdot 1$ & $73 \cdot 1$ & $73 \cdot 1$ & $73 \cdot 1$ \\
\hline Other $18: 1$ & 4.9 & $10 \cdot 4$ & $10 \cdot 4$ & $10 \cdot 4$ & $10 \cdot 4$ \\
\hline $20: 1 n-9 \dagger$ & 2.9 & $1 \cdot 4$ & $1 \cdot 4$ & $1 \cdot 4$ & $1 \cdot 4$ \\
\hline $22: 1 n-9$ & 0.5 & 0.5 & 0.5 & 0.5 & 0.5 \\
\hline Total monounsaturates & $92 \cdot 2$ & $85 \cdot 7$ & $85 \cdot 7$ & $85 \cdot 7$ & $85 \cdot 7$ \\
\hline $18: 2 n-6$ & 30.9 & 2.6 & $4 \cdot 2$ & 5.5 & $9 \cdot 3$ \\
\hline $18: 3 n-3$ & $10 \cdot 9$ & $<0.1$ & $<0.1$ & $<0.1$ & $<0.1$ \\
\hline Total PUFA & $41 \cdot 8$ & $2 \cdot 7$ & $4 \cdot 3$ & $5 \cdot 6$ & $9 \cdot 4$ \\
\hline trans-18: 1 & $<0.1$ & $33 \cdot 3$ & $33 \cdot 3$ & $33 \cdot 3$ & $33 \cdot 3$ \\
\hline$\Delta 9$ trans, 12 trans-18:2 & $<0.1$ & 0.4 & 0.4 & 0.4 & 0.4 \\
\hline$\Delta 9$ cis, 12 trans $-18: 2$ & $<0.1$ & $1 \cdot 6$ & 1.6 & $1 \cdot 6$ & 1.6 \\
\hline$\Delta 9$ trans, 12 cis-18:2 & 0.3 & 1.9 & 1.9 & 1.9 & 1.9 \\
\hline$\Delta 9$ cis, 13 trans $-18: 2 \ddagger$ & 0.3 & $2 \cdot 1$ & $2 \cdot 1$ & $2 \cdot 1$ & $2 \cdot 1$ \\
\hline Total cis,trans-18:2 & 0.6 & $6 \cdot 0$ & $6 \cdot 0$ & $6 \cdot 0$ & $6 \cdot 0$ \\
\hline
\end{tabular}

PUFA, polyunsaturated fatty acids.

* Rapeseed oil or partially hydrogenated rapeseed oil with or without addition of $18: 2 n-6$.

$\dagger \Delta 11$ cis-20: 1 may overlap with $18: 3$ isomers.

‡ May overlap with $\Delta 8$ trans, 12 cis- $18: 2$.

were killed immediately before the experiment after overnight fasting to provide a baseline value. The rats fed one of the experimental diets were then killed by exsanguination under $\mathrm{CO}_{2}$ anaesthesia after an overnight fast. Blood was collected via the abdominal aorta. The whole carcass (whole body-blood) was then stored at $-20^{\circ} \mathrm{C}$.

\section{Whole-carcass fatty acid analysis}

The whole carcass was blended three times using a meat grinder and mixed thoroughly as described previously (Yang et al. 1994; Chen et al. 1996). Total lipids were extracted from three aliquots (2 $\mathrm{g}$ each) using $20 \mathrm{ml}$ chloroform-methanol $(2: 1, \mathrm{v} / \mathrm{v})$ containing $0.02 \%(\mathrm{v} / \mathrm{v})$ butyrated hydroxytoluene (Sigma, St Louis, MO, USA) as an antioxidant (Folch et al. 1957). At the same time, heptadecanoic acid (17:0, 99\% purity; Sigma) was added as an internal standard to quantify the total carcass fatty acids. After homogenization, the bottom layer was taken and the three extracts were pooled and dried under a gentle stream of $\mathrm{N}_{2}$. The method used for extraction yielded $>95 \%$ recovery of tissue lipids (Folch et al. 1957; Ways \& Hanahan, 1964; Christie, 1982). The carcass total lipids (20 mg) were then converted to their corresponding fatty acid methyl esters (FAME) using $2 \mathrm{ml} 14 \%$ (v/v) $\mathrm{BF}_{3}$ in methanol and $1 \mathrm{ml}$ toluene at $90^{\circ} \mathrm{C}$ for $40 \mathrm{~min}$ under $\mathrm{N}_{2}$. FAME were then extracted by adding $5 \mathrm{ml}$ hexane and $1 \mathrm{ml}$ 
saline $(9 \mathrm{~g} \mathrm{NaCl} / \mathrm{l})$. After centrifugation, the hexane layer was taken and evaporated to $1 \mathrm{ml}$ under a gentle stream of $\mathrm{N}_{2}$. In some cases, the carcass lipids were transmethylated using $2 \mathrm{ml}$ methanolic hydrogen chloride. The results of the two methods of transmethylation were similar, as described previously (Zhang \& Chen, 1997); the data presented here were obtained by the $\mathrm{BF}_{3}$-methanol methylation method.

FAME in hexane were analysed initially by using an SP-2560 flexible fused silica capillary column $(100 \times$ $0.25 \mathrm{~mm}$ i.d., $20 \mu \mathrm{m}$ film thickness; Supelco, Beffefonte, PA, USA) in a Hewlett-Packard 5980 Series II gas chromatograph equipped with a flame-ionization detector (Hewlett-Packard, Palo Alto, CA, USA). The column temperature was programmed from 180 to $220^{\circ} \mathrm{C}$ at a rate of $1^{\circ} \mathrm{C} / \mathrm{min}$ and then held for $20 \mathrm{~min}$. Injection and detector temperatures were set at $250^{\circ} \mathrm{C}$, and the column head pressure was set at 15 psi. The individual fatty acids were then quantified according to the amount of heptadecanoic acid added (Chen et al. 1996). We found that $>96 \%$ of the heptadecanoic acid can be recovered. It should be pointed out that cis,trans-18:2 isomers, $\Delta 9$ cis, 12 cis-18:2 and trans-18:1 isomers extracted from tissue would have the same recovery relative to the amount of internal standard added.

Individual cis,trans-18:2 isomers and cis,trans-20:4 isomers were identified and determined as described previously (Ratnayake et al. 1994). In brief, the total trans- and cis-FAME were separated by $\mathrm{AgNO}_{3}$ TLC. The cis- or trans-FAME from the carcass lipids were saponified and acidified to the free fatty acids and then converted to their 2-alkenyloxazoline derivatives. The double-bond positions were confirmed by GLC-MS analysis of the 2-alkenyloxazoline derivatives. Determination of total trans-18:1 fatty acids was carried out by using $\mathrm{AgNO}_{3}$ TLC in conjunction with capillary GLC, as described previously (Ratnayake \& Bears-Rogers, 1990; Chen et al. 1995b) because a single-step and direct GLC cannot determine the total trans-18: 1 fatty acids due to overlap of the high $\Delta$ trans-18:1 isomer $(\Delta 12$ trans-18:0 to $\Delta 16$ trans-18:1) with the cis-18:1 isomer peak. The preparative $\mathrm{AgNO}_{3}$ TLC plates were prepared as described previously (Ratnayake \& Bears-Rogers, 1990). FAME $(15 \mathrm{mg})$ were subjected to a silica TLC plate in hexane solution and then developed in toluene at $-20^{\circ} \mathrm{C}$ for $3 \mathrm{~h}$. The separated trans-18:1 band was visualized under u.v. light $(254 \mathrm{~nm})$ and then scraped from the plate and extracted with hexane-chloroform $(1: 1, \mathrm{v} / \mathrm{v})$. After drying under $\mathrm{N}_{2}$, the trans-18:1 fraction was redissolved in hexane, and analysed by GLC as described earlier. The proportion of trans-18: 1 isomers $(\Delta 12$ trans- $18: 1$ to $\Delta 16$ trans- $18: 1)$ that overlapped with the cis-18:1 isomer peaks was calculated by comparing the $18: 1$ region of the GLC chromatogram of the isolated trans-18:1 fraction with that of the parent FAME mixture before $\mathrm{AgNO}_{3}$ fractionation. For this purpose, the trans-18:1 isomer peaks that were well separated from the cis peak serve as an internal standard. The total trans-18:1 content was then calculated by summing the proportions of the trans-18:1 isomers ( $\Delta 12$ trans $-18: 1$ to $\Delta 16$ trans-18:1) that overlapped with the cis-18:1 isomers and the well separated trans-18:1 isomers in the direct FAME analysis.

\section{Statistics}

Data are expressed as means and standard deviations. ANOVA followed by a least-significant difference test was used repeatedly for statistical evaluation of the differences among trans-18:1 isomers, $\Delta 9$ cis,12cis-18:2, $\Delta 9$ trans, 12 trans-18:2, $\Delta 9$ cis, 13 trans-18:2, $\Delta 9$ cis, 13 trans-18:2, $\Delta 9$ trans, 12 cis-18:2 and total cis,trans-18:2 isomers within the same diet. This analysis was performed using ANOVA software on a personal computer (PC ANOVA for the IBM Personal Computer, version 1.1; IBM, Armonk, NY, USA).

\section{Results \\ Fatty acid composition of dietary fat}

Dietary group A was fed a reference diet containing rapeseed oil. The fatty acid content $(\mathrm{g} / \mathrm{kg}$ diet) of diets $\mathrm{B}-\mathrm{E}$ was the same except for the amount of $\Delta 9$ cis, 12 cis-18:2 (Table 1), which was increased from $2 \cdot 6$ to $9 \cdot 3 \mathrm{~g} / \mathrm{kg}$. Dietary $\Delta 9$ cis, 12 cis-18: 2 expressed as a percentage of total energy was 0.56 in $\operatorname{diet} \mathrm{B}, 0.81$ in $\operatorname{diet} \mathrm{C}, 1.06$ in $\operatorname{diet} \mathrm{D}$, and 1.81 in diet $\mathrm{E}$. The total cis,trans $-18: 2$ isomers accounted for $6.0 \mathrm{~g} / \mathrm{kg}$ diet $(1.72 \%$ total energy), with $\Delta 9 \mathrm{cis}, 13$ trans-18: 2 being a major isomer followed by $\Delta 9$ trans, 12 cis-18:2 and $\Delta 9$ cis, 12 trans-18:2. In contrast, the total trans-18: 1 isomers accounted for $33.3 \mathrm{~g} / \mathrm{kg}$ diet $(7 \cdot 17 \%$ total energy), whereas $\Delta 9$ cis $-18: 1$ was $73 \cdot 1 \mathrm{~g} / \mathrm{kg}$ diet $(15.7 \%$ total energy).

\section{Food consumption and body weight}

The rats fed on different diets with varying levels of $\Delta 9$ cis, 12cis-18:2 supplementation consumed similar amounts of food $(17 \cdot 0-18 \cdot 5 \mathrm{~g}$ diet/rat per d). No significant differences in body-weight gain expressed as either $\mathrm{g} / \mathrm{d}$ or $\mathrm{g} / \mathrm{g}$ diet were detected between the dietary groups (Table 2).

\section{Apparent oxidation of cis,trans-18:2 isomers}

Accumulation is defined as the whole-body increase in levels of a fatty acid, whereas apparent oxidation is the whole-body utilization (disappearance) in relation to its intake for a given period. The following equations were used to calculate the accumulation and apparent oxidation of cis,trans-18:2 isomers in the whole body:

$$
\begin{aligned}
\text { accumulation }(\mathrm{mg} / \mathrm{rat})= & (\text { final body content } \\
& - \text { initial body content }),
\end{aligned}
$$

apparent oxidation (\% dietary intake)

$=($ intake - excretion - accumulation - LCP $) /$ intake $\times 100$,

where excretion was assumed to be $2 \%$ of the total dietary fatty acids (Yang et al. 1994); LCP is the amount of the longer-chain products in the desaturation and elongation pathway. In this regard, the LCP for $\Delta 9$ cis, 12 cis-18:2 would include $\Delta 6$ cis,9cis,12cis-18:3, $\Delta 11$ cis, 14 cis-20:2, $\Delta 8$ cis,11cis,14cis-20:3, $\Delta 5$ cis, 8 cis, 11 cis,14cis-20:4, $\Delta 7$ cis, 
Table 2. Body weight and daily food intake of rats fed diets containing non-hydrogenated (diet $A$ ) or partially hydrogenated rapeseed oil with $1.72 \%$ energy as cis,trans-18:2 isomer (diet B) and varying amounts of $\Delta 9$ cis, 12 cis-18:2 (diets C-E)

(Mean values and standard deviations for ten rats)

\begin{tabular}{|c|c|c|c|c|c|c|c|c|c|c|}
\hline \multirow[t]{2}{*}{ Diet...* } & \multicolumn{2}{|c|}{$A$} & \multicolumn{2}{|c|}{ B } & \multicolumn{2}{|c|}{$\mathrm{C}$} & \multicolumn{2}{|c|}{$\mathrm{D}$} & \multicolumn{2}{|c|}{$E$} \\
\hline & Mean & SD & Mean & SD & Mean & SD & Mean & SD & Mean & SD \\
\hline Initial body wt (g) & 67 & 6 & 65 & 5 & 66 & 4 & 64 & 4 & 67 & 6 \\
\hline Final body wt (g) & 230 & 11 & 211 & 13 & 237 & 17 & 219 & 2 & 216 & 15 \\
\hline Body-wt gain ( $\mathrm{g} / \mathrm{d}$ per rat) & 7.8 & 0.4 & 7.0 & 0.5 & 8.1 & 0.6 & $7 \cdot 4$ & 0.4 & 7.1 & 0.5 \\
\hline Food intake $(\mathrm{g})$ & $17 \cdot 0$ & $4 \cdot 3$ & $18 \cdot 0$ & 3.5 & 18.5 & 3.8 & $17 \cdot 5$ & 4.0 & $18 \cdot 2$ & $4 \cdot 3$ \\
\hline Body-wt gain (g/rat per g diet) & 0.46 & 0.11 & 0.39 & 0.08 & 0.44 & 0.09 & 0.42 & $0 \cdot 10$ & 0.39 & 0.09 \\
\hline
\end{tabular}

${ }^{*}$ For details of diets and procedures, see Table 1 and p. 250.

$10 \mathrm{cis}, 13 \mathrm{cis}, 16 \mathrm{cis}-22: 4$ and $\Delta 4 \mathrm{cis}, 7 \mathrm{cis}, 10 \mathrm{cis}, 13 \mathrm{cis}, 16 \mathrm{cis}-$ $22: 5$, whereas the LCP for $\Delta 9$ cis,13trans $-18: 2$ and $\Delta 9$ cis, 12 trans $-18: 2$ would include $\Delta 5 \mathrm{cis}, 8 \mathrm{cis}, 11 \mathrm{cis}$, 15trans-20:4 and $\Delta 5$ cis,8cis,11cis,14trans-20:4, respectively (Kwan et al. 1998; Ratnayake et al. 1994). No other LCP for cis,trans-18:2 isomers and trans-18:1 isomers was found in the carcass lipids.

Values for accumulation and apparent oxidation of total trans-18:1 isomers, total cis,trans-18:2 isomers and $\Delta 9$ cis, 12 cis-18:2 are summarized in Table 3. About 78$82 \%$ of the total trans-18:1 isomers were apparently oxidized in dietary groups $\mathrm{B}-\mathrm{E}$; this means that only 18 $22 \%$ of the total dietary trans-18:1 isomers were accumulated in the body during the 3 weeks of the experiment. For $\Delta 9$ cis, 12 cis- $18: 2,67 \%$ of the total dietary intake in dietary group A (the reference diet) was apparently oxidized in contrast with $38-51 \%$ in dietary groups BE. For $\Delta 9$ trans, 12 trans- $18: 2$, about $85-92 \%$ of the dietary intake was apparently oxidized in dietary groups B-E. For $\Delta 9$ cis,13trans-18:2, 68-72\% of the dietary intake was apparently oxidized. For $\Delta 9$ cis, 12 trans $-18: 2$ and $\Delta 9$ trans, 12 cis- $18: 2$, the apparent oxidation was similar $(71-78 \%$ of the dietary intake). Overall, about $72-76 \%$ of the total dietary intake of cis,trans-18:2 isomers were apparently oxidized (Table 3 ).

Compared with that of $\Delta 9$ cis, 12 cis-18:2, the apparent oxidation of all cis,trans-18:2 isomers was greater (72$76 \%$ v. $38-51 \%$ ), but it was similar to that of total trans$18: 1$ isomers except for $\Delta 9$ trans, 12 trans-18:2 (Table 3). Among four cis,trans-18:2 isomers, the apparent oxidation of $\Delta 9$ trans,12trans-18:2 was greatest, while those of $\Delta 9$ cis, 13 trans- $18: 2, \Delta 9$ cis, 12 trans- $18: 2$ and $\Delta 9$ trans, $12-$ cis-18:2 were very similar.

Two cis,trans-18:2 isomers, $\Delta 9$ cis,13trans $-18: 2$ and $\Delta 9$ cis,12trans-18:2, can be chain-elongated and desaturated to form $\Delta 5 \mathrm{cis}, 8 \mathrm{cis}, 11 \mathrm{cis}, 15$ trans- $20: 4$ and $\Delta 5 \mathrm{cis}, 8 \mathrm{cis}$, 11cis,14trans-20:4 respectively (Kwan et al. 1998; Ratnayake et al. 1994). Among groups B-E the wholebody partitioning of $\Delta 9$ cis, 13 trans $-18: 2$ was $68-72 \%$ to apparent oxidation, $25-31 \%$ to accumulation, and $0.9-$ $2.7 \%$ to the LCP. Similarly, the whole-body partitioning of $\Delta 9$ cis, 12 trans $-18: 2$ was $71-76 \%$ to apparent oxidation, $23-28 \%$ to accumulation, and $0 \cdot 2-1.8 \%$ to LCP. In contrast, the whole-body partitioning of $\Delta 9 \mathrm{cis}, 12 \mathrm{cis}-18: 2$ in groups $\mathrm{B}-\mathrm{E}$ was $38-51 \%$ to apparent oxidation, $3-17 \%$ to accumulation and $31-57 \%$ to LCP corresponding to its amount in diet, i.e. a higher amount in the diet is associated with a higher percentage partitioning to apparent oxidation and a lower percentage partitioning to accumulation.

The accumulation of LCP for cis,trans-18:2 isomers decreased with increasing dietary $\Delta 9$ cis, 12 cis-18:2 (Table $3)$. Accumulation of the LCP $(\Delta 5 \mathrm{cis}, 8 \mathrm{cis}, 11 \mathrm{cis}, 15$ trans$20: 4$ ) derived from $\Delta 9$ cis, 13 trans- $18: 2$ decreased from 22 to $7 \mathrm{mg} / \mathrm{rat}$ when dietary $\Delta 9$ cis, 12 cis-18:2 was increased from 0.56 to $1.81 \%$ total energy. Similarly, the accumulation of the LCP $(\Delta 5$ cis,8cis,11cis,14trans-20:4) derived from $\Delta 9$ cis, 12 trans-18: 2 decreased from 11 to $<1 \mathrm{mg} / \mathrm{rat}$ when $\Delta 9$ cis, 12 cis-18:2 was gradually increased in the diet.

\section{Discussion}

The balance method has been shown to be as accurate as indirect calorimetry for determining energy expenditure (Rothwell \& Stock, 1982). The present study applied the balance method to the estimation of the apparent oxidation of cis,trans-18:2 isomers relative to that of $\Delta 9 \mathrm{cis}, 12$ cis 18:2. We are unaware of any studies using either radiolabelled fatty acids as tracers, or other methods of estimating whole-body oxidation and accumulation of cis,trans-18:2 isomers. The present study was restricted to the estimation of whole-body partitioning of cis,trans$18: 2$ isomers (accumulation, elongation and desaturation to LCP and apparent oxidation) relative to that for $\Delta 9$ cis, $12 \mathrm{cis}$ $18: 2$ and trans-18:1 isomers, because none of these fatty acids can be synthesized by mammals and their intake represents only the net change in their availability. The estimation of whole-body partitioning of saturates and monounsaturates $(18: 0, \Delta 9$ cis- $18: 1,16: 0, \Delta 9$ cis- $16: 1)$ is inappropriate, because it is impossible to differentiate the proportion diverting to oxidation and accumulation from the diet or de novo synthesis.

The present study demonstrated that whole-body partitioning of cis,trans-18:2 isomers is different from that of $\Delta 9$ cis, 12 cis-18:2. First, $72-76 \%$ of the dietary cis,trans $-18: 2$ isomers but only $41-52 \%$ of the dietary $\Delta 9$ cis, 12 cis-18:2 in groups B-E was diverted to oxidation $(P<0.05$; Table 3$)$, suggesting that cis,trans-18:2 isomers are more likely to be oxidized than their cis counterpart $\Delta 9$ cis, 12 cis-18:2. Second, $<3 \%$ of the dietary $\Delta 9$ cis, 13 trans-18:2 and $\Delta 9$ cis, 12 trans-18:2 were diverted to LCP as compared with dietary $\Delta 9$ cis, 12 cis-18:2, 31-57\% of which was chain-elongated and desaturated to LCP in groups $\mathrm{B}-\mathrm{E} \quad(P<0.05)$; this finding indicates that $\Delta 9$ cis, 12 cis-18:2 is a better substrate than cis,trans $-18: 2$ 
Table 3. Intake, whole-body accumulation and apparent oxidation of linoleic acid ( $\Delta 9 \mathrm{cis}, 12 \mathrm{cis}-18: 2)$, total trans-18:1 and cis-trans-18:2 isomers during a $21 \mathrm{~d}$ experimental period in rats fed diets containing non-hydrogenated (diet A) or partially hydrogenated rapeseed oil with $1.72 \%$ energy as cis, trans $-18: 2$ isomers (diet B) and varying amounts of $\Delta 9$ cis, 12 cis-18:2 (diets C-E)

(Mean values and standard deviations)

\begin{tabular}{|c|c|c|c|c|c|c|c|c|c|c|c|c|c|c|}
\hline & & & & & & & & & & & \multicolumn{4}{|c|}{ Oxidized } \\
\hline & \multicolumn{2}{|c|}{$\begin{array}{l}\text { Initial intake } \\
(\mathrm{mg} / \mathrm{rat})^{*}\end{array}$} & \multicolumn{2}{|c|}{$\begin{array}{c}\text { Final intake } \\
\text { (mg/rat) }\end{array}$} & \multicolumn{2}{|c|}{$\begin{array}{l}\text { Accumulated } \\
\text { (mg/rat) }\end{array}$} & \multicolumn{2}{|c|}{$\begin{array}{l}\text { Ingested } \\
\text { (mg/rat)† }\end{array}$} & \multicolumn{2}{|c|}{$\begin{array}{c}\text { Accumulated } \\
\text { as LCP } \\
\text { (mg/rat) } \ddagger\end{array}$} & \multicolumn{2}{|c|}{$\mathrm{mg} / \mathrm{rat}$} & \multicolumn{2}{|c|}{$\begin{array}{c}\% \\
\text { ingested§ }\end{array}$} \\
\hline & Mean & SD & Mean & SD & Mean & SD & Mean & SD & Mean & SD & Mean & SD & Mean & SD \\
\hline \multicolumn{15}{|l|}{ Diet A } \\
\hline trans-18: 1 & 39 & 22 & ND & - & ND & - & ND & - & ND & - & ND & - & ND & - \\
\hline$\Delta 9$ cis, 12 cis-18:2 & 760 & 67 & 3417 & 613 & 2657 & 476 & 11316 & 2241 & 1125 & 178 & 7534 & 669 & 67 & 6 \\
\hline$\Delta 9$ trans, 12 cis-18:2 & $<1$ & - & ND & - & ND & - & ND & - & ND & - & ND & - & ND & - \\
\hline$\Delta 9$ cis, 13 trans $-18: 2$ & $<1$ & - & ND & - & ND & - & ND & - & ND & - & ND & - & ND & - \\
\hline$\Delta 9$ cis, 12 trans $-18: 2$ & 4 & 1 & ND & - & ND & - & ND & - & ND & - & ND & - & ND & - \\
\hline$\Delta 9$ trans, 12 cis-18:2 & 4 & 1 & ND & - & ND & - & ND & - & ND & - & ND & - & ND & - \\
\hline Total cis, trans-18:2 & 9 & 2 & ND & - & ND & - & ND & - & ND & - & ND & - & ND & - \\
\hline \multicolumn{15}{|l|}{ Diet B } \\
\hline trans-18: 1 & 39 & 22 & 2623 & 341 & 2593 & 336 & 14047 & 2583 & 0 & - & 11454 & 422 & $82^{a b}$ & 3 \\
\hline$\Delta 9$ cis, 12 cis-18:2 & 760 & 67 & 786 & 87 & 26 & 4 & 996 & 189 & 575 & 104 & 396 & 129 & $40^{d}$ & 13 \\
\hline$\Delta 9$ trans, 12 cis- $18: 2$ & $<1$ & - & 20 & 14 & 19 & 13 & 159 & 30 & 0 & - & 140 & 13 & $88^{\mathrm{a}}$ & 9 \\
\hline$\Delta 9$ cis, 13 trans-18:2 & $<1$ & - & 202 & 39 & 201 & 38 & 791 & 150 & 22 & 5 & 568 & 41 & $72^{c}$ & 5 \\
\hline$\Delta 9$ cis, 12 cis $-18: 2$ & 4 & 1 & 147 & 29 & 144 & 27 & 616 & 117 & 11 & 2 & 461 & 32 & $75^{\mathrm{bc}}$ & 5 \\
\hline$\Delta 9$ trans, 12 cis- $18: 2$ & 4 & 1 & 170 & 25 & 166 & 23 & 752 & 142 & 0 & - & 586 & 68 & $78^{\mathrm{b}}$ & 3 \\
\hline Total cis,trans-18:2 & 9 & 2 & 539 & 93 & 530 & 91 & 2318 & 436 & 34 & 6 & 1754 & 72 & $76^{\mathrm{b}}$ & 3 \\
\hline \multicolumn{15}{|l|}{ Diet C } \\
\hline trans-18: 1 & 39 & 22 & 3221 & 629 & 3182 & 621 & 14314 & 2871 & 0 & - & 11132 & 566 & $78^{\mathrm{b}}$ & 4 \\
\hline$\Delta 9$ cis, 12 cis- $18: 2$ & 760 & 67 & 939 & 151 & 242 & 39 & 1641 & 328 & 784 & 171 & 615 & 209 & $38^{\mathrm{d}}$ & 15 \\
\hline$\Delta 9$ trans, 12 cis-18:2 & $<1$ & - & 16 & 10 & 15 & 9 & 151 & 29 & 0 & - & 136 & 13 & $90^{\mathrm{a}}$ & 13 \\
\hline$\Delta 9$ cis, 13 trans $-18: 2$ & $<1$ & - & 245 & 64 & 244 & 63 & 787 & 157 & 15 & 5 & 528 & 58 & $67^{\mathrm{C}}$ & 8 \\
\hline$\Delta 9$ cis, 12 trans- $18: 2$ & 4 & 1 & 163 & 46 & 159 & 46 & 621 & 124 & 7 & 2 & 455 & 50 & $73^{\mathrm{bc}}$ & 8 \\
\hline$\Delta 9$ trans, 12 cis- $18: 2$ & 4 & 1 & 209 & 44 & 205 & 42 & 768 & 154 & 0 & - & 563 & 46 & $74^{\mathrm{bc}}$ & 6 \\
\hline Total cis,trans-18:2 & 9 & 2 & 633 & 156 & 623 & 151 & 2328 & 465 & 23 & 6 & 1682 & 167 & $72^{\mathrm{bc}}$ & 7 \\
\hline \multicolumn{15}{|l|}{ Diet D } \\
\hline trans-18: 1 & 39 & 22 & 2876 & 543 & 2837 & 536 & 13892 & 2926 & 0 & - & 11055 & 557 & $80^{\mathrm{ab}}$ & 4 \\
\hline$\Delta 9$ cis, 12 cis-18:2 & 760 & 67 & 102 & 164 & 266 & 43 & 2061 & 431 & 844 & 172 & 951 & 310 & $46^{\mathrm{C}}$ & 15 \\
\hline$\Delta 9$ trans, 12 cis-18:2 & $<1$ & - & 21 & 16 & 20 & 13 & 131 & 28 & 0 & - & 111 & 20 & $85^{\mathrm{a}}$ & 15 \\
\hline$\Delta 9$ cis, 13 trans $-18: 2$ & $<1$ & - & 226 & 49 & 225 & 48 & 735 & 154 & 13 & 5 & 497 & 52 & $68^{\mathrm{b}}$ & 7 \\
\hline$\Delta 9$ cis 12 trans $-18: 2$ & 4 & 1 & 16 & 34 & 166 & 33 & 580 & 122 & 5 & 2 & 409 & 36 & $71^{\mathrm{b}}$ & 6 \\
\hline$\Delta 9$ trans, 12 cis-18:2 & 4 & 1 & 184 & 39 & 180 & 39 & 719 & 151 & 0 & - & 539 & 37 & $75^{\mathrm{b}}$ & 5 \\
\hline Total cis, trans-18:2 & 9 & 2 & 600 & 122 & 591 & 119 & 2166 & 455 & 18 & 7 & 1557 & 129 & $72^{b}$ & 6 \\
\hline \multicolumn{15}{|l|}{ Diet $E$} \\
\hline trans-18: 1 & 39 & 22 & 2818 & 496 & 2779 & 515 & 13527 & 3114 & 0 & - & 10748 & 541 & $80^{b}$ & 4 \\
\hline$\Delta 9$ cis, 12 cis-18:2 & 760 & 67 & 1349 & 208 & 589 & 91 & 3470 & 764 & 1108 & 215 & 1773 & 348 & $51^{\mathrm{c}}$ & 10 \\
\hline$\Delta 9$ trans, 12 cis- $18: 2$ & $<1$ & - & 14 & 11 & 13 & 9 & 153 & 34 & 0 & - & 140 & 20 & $92^{\mathrm{a}}$ & 11 \\
\hline$\Delta 9$ cis,13trans-18:2 & $<1$ & - & 209 & 54 & 208 & 43 & 752 & 165 & 7 & 4 & 537 & 54 & $71^{\mathrm{b}}$ & 7 \\
\hline$\Delta 9$ cis, 12 trans $-18: 2$ & 4 & 1 & 147 & 57 & 143 & 56 & 588 & 129 & 1 & 1 & 444 & 50 & $76^{\mathrm{b}}$ & 10 \\
\hline$\Delta 9$ trans, 12 cis-18:2 & 4 & 1 & 175 & 39 & 171 & 39 & 724 & 159 & 0 & - & 553 & 37 & $77^{\mathrm{b}}$ & 5 \\
\hline Total cis,trans-18:2 & 9 & 4 & 545 & 138 & 535 & 136 & 2217 & 487 & 8 & 5 & 1674 & 133 & $76^{\mathrm{b}}$ & 6 \\
\hline
\end{tabular}

LCP, longer-chain products; ND, not determined.

a,b,c,d Means within a dietary group with different superscript letters were significantly different $(P<0.05)$.

* The initial values are mean of six rats killed before the experimental period, while the remaining values were means for ten rats.

† Assuming that $2 \%$ of the dietary fatty acids was excreted.

‡LCP of linoleic acid ( $\Delta 9 \mathrm{cis}, 12 \mathrm{cis}-18: 2)$ include $\Delta 6 \mathrm{cis}, 9 \mathrm{cis}, 12 \mathrm{cis}-18: 3, \Delta 11 \mathrm{cis}, 14 \mathrm{cis}-20: 2, \Delta 8 \mathrm{cis}, 11 \mathrm{cis}, 14 \mathrm{cis}-20: 3, \Delta 5 \mathrm{cis}, 8 \mathrm{cis}, 11 \mathrm{cis}, 14 \mathrm{cis}-20: 4, \Delta 7 \mathrm{cis}, 10 \mathrm{cis}$, $13 \mathrm{cis}, 16 \mathrm{cis}-22: 4$ and $\Delta 4 \mathrm{cis}, 7 \mathrm{cis}, 10 \mathrm{cis}, 13 \mathrm{cis}, 16 \mathrm{cis}-22: 5$. LCP of $\Delta 9 \mathrm{cis}, 13$ trans-18:2 includes $\Delta 5 \mathrm{cis}, 8 \mathrm{cis}, 11 \mathrm{cis}, 15 \mathrm{trans}-20: 4$. LCP of $\Delta 9 \mathrm{cis}, 12 \mathrm{trans}-18: 2$ includes $\Delta 5$ cis, 8 , cis, 11 cis, 14 trans-20: 4 .

$\S$ Oxidized $(\%$ ingested $)=($ intake - excretion - accumulation - LCP $) /$ intake $\times 100$

isomers for desaturase and elongase. Third, $22-24 \%$ of the total dietary cis,trans-18:2 isomers was accumulated in the body. In contrast, only $3-17 \%$ of the dietary $\Delta 9$ cis, 12 cis-18:2 was retained in the body. Among the four cis,trans-18:2 isomers, it appears that the apparent oxidation of $\Delta 9$ trans, 12 trans-18:2 was greater than that of the other three isomers including $\Delta 9$ cis,13trans-18:2, $\Delta 9$ cis, 12 trans- $18: 2$ and $\Delta 9$ trans, 12 cis- $18: 2$.

The oxidation of trans-fatty acids in vivo and in vitro has been studied extensively by using radioisotopic methods (Lawson \& Holman, 1981; Menon \& Dhopeshwarkar, 1983; Ide \& Sugano, 1984; Lanser et al. 1986; Delany \& Bray, 1993; Berdeaux et al. 1998; Bretillon et al. 1998; Beyer \& Emken, 1991). Lawson \& Holman (1981) found that rat heart and liver mitochondria oxidized cis-18:1 isomers significantly more rapidly than their respective trans-isomers. Similarly, Lanser et al. (1986) demonstrated that oleic acid was oxidized $35-40 \%$ faster than elaidic acid by rat 
heart homogenates, whereas human heart homogenates oxidized these fatty acids at similar rates. In contrast, Ide \& Sugano (1984) found that perfused liver oxidized 9transoctadecenoic acid more rapidly than its cis-isomer. These conflicting reports clearly suggest that it is inappropriate to compare these published data; Lawson \& Holman (1981) and Lanser et al. (1986) used isolated mitochondria or heart and liver homogenates, whereas Ide \& Sugano (1984) used the perfused liver, which is more relevant physiologically than the former. The present results are in agreement with those of Ide \& Sugano (1984), who also demonstrated that trans-octadecadienoic acid is oxidized faster than the cis-isomer. This finding further demonstrated that isolated mitochondria and organs may not necessarily reflect the complex interplay of the various metabolic pathways involved in utilization of a fatty acid in an intact animal. Although the balance method used in the present study may have many limitations, it measures the oxidation of trans-fatty acids in intact animals and also over a longer period.

Failure to measure the amount of cis,trans-18:2 isomers, trans-18:1 isomers and $\Delta 9$ cis, 12 cis-18:2 present in the digestive system and faeces may lead to overestimation of their accumulation and apparent oxidation. However, the animals were killed after overnight fasting and it was assumed that the digestion and absorption of dietary fat were completed. The present study did not measure the faecal excretion of cis,trans-18:2 isomers, trans-18:1 isomers or $\Delta 9$ cis, 12 cis-18:2. We assume that this factor would not significantly affect the estimation. First, although it cannot transfer directly to the present study, our previous study showed that faecal excretion is $<2 \%$ of the dietary total fat (Yang et al. 1994) and it would not significantly affect the estimation of apparent oxidation of these cis,trans-18:2 isomers (2\% intake was lost in faeces $v$. $72-77 \%$ intake was oxidized). Second, the objective of the study was to compare the apparent oxidation of cis,trans-18: 2 isomers relative to that of $\Delta 9$ cis, 12 cis- $18: 2$ and trans-18:1 isomers. No data have shown that cis,trans-18:2 isomers were absorbed differently from trans-18: 1 isomers, $\Delta 9$ cis, 12 cis- $18: 2$ and other fatty acids. Regarding the effectiveness of extraction, first, previous reports have shown that using methanol-chloroform $(2: 1$, v/v) could yield $>95 \%$ recovery of tissue lipids (Folch et al. 1957; Ways \& Hanahan, 1964; Christie, 1982). Second, there have been no data showing that the effectiveness of extraction of cis,trans-18:2 isomers is different from that of $\Delta$ cis, 12 cis-18:2 and trans-18:1 isomers, and so relative oxidation of cis,trans-18:2 isomers would be underestimated to the same extent as that for $\Delta 9$ cis, 12 cis-18:2 and trans-18:1 isomers, if indeed there is any deviation.

The reliability of balance method also depends on accurate GLC measurement of fatty acids in the diet, initial and final body content, and their corresponding LCP. The instrumental error for GLC analysis of $\Delta 9$ cis, 12 cis-18:2, total $\Delta 9$ cis, 12 cis-18: 2 isomers and trans-18: 1 fatty acids in groups $\mathrm{B}-\mathrm{E}$ was $<2 \%$. In contrast, it was $>10 \%$ for $\Delta 9$ cis, 12 cis, 15 cis-18:3 due to a trace amount of this fatty acid in the PHRO. Thus, the reliability of balance method may not apply to the minor fatty acids that cannot be measured accurately by GLC analysis. In this regard, the apparent oxidation and accumulation of cis,trans-18:2 isomers and trans-18:1 fatty acids were not determined in rats fed diet A containing the non-hydrogenated rapeseed oil, because the quantities of these fatty acids are relatively minor. For the same reason, the apparent oxidation of $\Delta 9$ cis, 12 cis, 15 cis-18:3 was not estimated in rats fed diets $\mathrm{B}-\mathrm{E}$, because it only accounted for $<0.01 \%$ of the total fat. In contrast, for diets $\mathrm{B}-\mathrm{E}$ containing $\mathrm{PHRO}$ in which trans-18: 1 fatty acids and cis,trans-18:2 isomers were 23 and $5.5 \%$ of the total fatty acids respectively, GLC analysis is sensitive enough to measure them accurately. Thus, the data on apparent oxidation of these fatty acids should be reliable. It was noticed that the animals showed no sign of $n-3$ fatty acid deficiency during the 3 -week balance period, although diets $\mathrm{B}-\mathrm{E}$ were low in $\Delta 9 \mathrm{cis}, 12 \mathrm{cis}, 15 \mathrm{cis}-18: 3$.

From the results for whole-body fatty acid balance presented here, we conclude that most of dietary cis,trans-18:2 isomers $(>70 \%)$ is diverted to oxidation, $<24 \%$ is accumulated in the body and only a small percentage $(<3)$ is desaturated and chain-elongated to the unusual trans-LCP.

\section{Acknowledgements}

We thank the Hong Kong Research Grant Council for support of this project. David Forster and Greg Hatfield (CanAmera Foods, Toronto, Ont., Canada) are thanked for preparation of PHRO.

\section{References}

Berdeaux O, Blond JP, Bretillon L, Chardigny JM, Mairot T, Vatele JM, Poullain D \& Sebedio JL (1998) In vitro desaturation or elongation of monotrans isomers of linoleic acid by rat liver microsomes. Molecular and Cellular Biochemistry 185, 17-25.

Berdeaux O, Chardigny JM, Sebedio JL, Mairot T, Poullain D, Vatele JM \& Noel JP (1996) Effect of a trans isomer of arachidonic acid on rat platelet aggregation and eicosanoid production. Journal of Lipid Research 37, 2244-2250.

Beyer EC \& Emken EA (1991) Metabolite of cis,trans, and trans,cis isomers of linoleic acid in mice and incorporation into tissue lipid. Biochimica et Biophysica Acta 1082, 275-284.

Bretillon L, Chardigny JM, Noel JP \& Sebedio JL (1998) Desaturation and chain elongation of [1-14C] mono-trans isomers of linoleic and alpha-linolenic acid in perfused rat liver. Journal of Lipid Research 39, 2228-2236.

Chen ZY, Menard CR \& Cunnane SC (1996) Accumulation of polyunsaturates is decreased by weight-cycling: whole body analysis in young, growing rats. British Journal of Nutrition $\mathbf{7 5}$, 583-591.

Chen ZY, Ratnayake WMN, Fortier L, Ross R \& Cunnane SC (1995a) Similar distribution of trans fatty acid isomers in partially hydrogenated vegetable oil and adipose tissue of Canadians. Canadian Journal of Physiology and Pharmacology 73, 718-723.

Chen ZY, Ratnayake WMN, Hollywood R \& Pelletier G (1995b) Trans fatty acid isomers in Canadian human milk. Lipids 30, $15-30$.

Christie WW (1982) Lipid Analysis, 2nd ed. New York: Pergamon Press.

Delany IP \& Bray GA (1993) Differential oxidation of various fatty acids. Obesity Research 1, 415-417. 
Folch J, Lee M \& Stanley GHS (1957) A simple method for the isolation and purification of total lipids from animal tissues. Journal of Biological Chemistry 226, 497-509.

Hill E, Koletzko B \& Miller J (1990) Cis- and trans-isomeric fatty acids in plasma lipids of newborn infants and their mothers. Biology of the Neonate 57, 172-178.

Holman RT, Pusch F, Svingen B \& Dutton HJ (1991) Unusual isomers of polyunsaturated fatty acids in liver phospholipids of rats fed hydrogenated oil. Proceedings of the National Academy of Sciences USA 88, 4830-4834.

Ide T \& Sugano M (1984) Oxidation and esterification of cis and trans-isomers of octadecenoic and octadecadienoic acids in isolated rat liver. Biochimica et Biophysica Acta 794, 281-291.

Koletzko B (1992) Trans fatty acids may impair biosynthesis of long-chain polyunsaturated fatty acids and growth in man. Acta Paediatrica 81, 302-306.

Kwan KK, Wang LY, Chan KP \& Chen ZY (1998) Inhibitory effect of linoleic acid on chain elongation and desaturation of $18: 2 \mathrm{c}, \mathrm{t}$ isomers in lactating and neonatal rats. Lipids 33, 409-416.

Lanser AC, Emken EA \& Ohlrogge JB (1986) Oxidation of oleic and elaidic acids in rat and human heart homogenates. Biochimica et Biophysica Acta 875, 510-515.

Lawson LD \& Holman RT (1981) Beta-oxidation of the geometric and positional isomers of octadecenoic acid by rat heart and liver mitochondria. Biochimica et Biophysica Acta 665, 60-65.

Menon NK \& Dhopeshwarkar GA (1983) Differences in the fatty acid profile and $\beta$-oxidation by heart homogenates of rats fed cis and trans octadecenoic acids. Biochimica et Biophysica Acta 751, 14-20.

Ratnayake WMN \& Bears-Rogers JL (1990) Problems of analysis C18:1 cis- and trans-fatty acids of margarine on the SP-2340 capillary column. Journal of Chromatographic Science 28, 633-639.

Ratnayake WMN, Chen ZY, Pelletier G \& Weber D (1994) Occurrence of $5 \mathrm{c}, 8 \mathrm{c}, 11 \mathrm{c}, 15 \mathrm{t}$-eicosatetraenoic acid and other unusual polyunsaturated fatty acids in rats fed partially hydrogenated canola oil. Lipids 29, 707-714.

Ratnayake WMN, Hollywood R, O’Grady E \& Pelletier G (1993) Fatty acid isomers in some common foods items in Canada. Journal of the American College of Nutrition 12, 651-660.

Ratnayake WMN \& Pelletier G (1992) Positional and geometrical isomers of linoleic acid in partially hydrogenated oils. Journal of American Oil Chemists' Society 69, 95-105.

Rothwell NJ \& Stock MJ (1982) Energy expenditure of 'cafeteria'fed rats determined from measurements of energy balance and indirect calorimetry. Journal of Physiology 326, 371-377.

Ways P \& Hanahan DJ (1964) Charaterization and quantification of red cell lipids in normal man. Journal of Lipid Research $\mathbf{5}$, $318-328$

Yang J, Chen ZY \& Cunnane SC (1994) Application of the balance method to determining accumulation, metabolism and apparent oxidation of linoleic acid and $\alpha$-linolenic acids in the pregnant rat. Metabolism 43, 940-944.

Zhang A \& Chen ZY (1997) Oxidative stability of conjugated linoleic acids relative to other polyunsaturated fatty acids. Journal of American Oil Chemists' Society 74, 1611-1613. 